\title{
SIMULATION RESEARCH ON THE PROCESS OF LANE CHANGE BY A MOTOR VEHICLE STEERED IN AN OPEN- AND CLOSED-LOOP SYSTEM
}

\author{
MIROSŁAW GIDLEWSKI ${ }^{1,3}$, LESZEK JEMIOŁ ${ }^{3} \&$ DARIUSZ ŻARDECKI ${ }^{2}$ \\ ${ }^{1}$ Automotive Industry Institute, Warszawa, Poland \\ ${ }^{2}$ Military University of Technology, Warszawa, Poland \\ ${ }^{3}$ University of Technology and Humanities, Radom, Poland
}

\begin{abstract}
Within a more extensive research project, analytic work and simulation research was undertaken on the use of an active steering system for the automatic performing of a lane-change manoeuvre. Based on the general optimal control theory, a controller algorithm was developed, where a simplified reference model of the lateral dynamics of a motor vehicle, known as a "bicycle model", was used. The controller generates a reference signal of the steering wheel angle and corrects this signal by means of Kalman regulators, applied to minimize the deviations between the reference and actual signals representing the variables that describe the vehicle trajectory. In spite of quite complicated functions, the algorithm having been developed is characterized by a simple and, at the same time, effective analytical description. For the algorithm to be validated, it was subjected to extensive simulation tests. In these tests, the steered object was a two-axle motor truck of medium load capacity, driven with quite a high speed. The vehicle model (3D, nonlinear, of the multi-body simulation (MBS) type, experimentally verified) made it possible to describe the vehicle dynamics even in extremely difficult operation conditions, where wheel lift-off and significant tyre slip values may also be encountered. In this paper, a fragment of this work has been reported, with presenting information about the controller and results of simulation testing of the dynamics of the lane-change process performed in an open-loop system (without regulators) and in a closed-loop system (with regulators) for different variants of model parameters. To assess the effects of changes in the model parameters, not only comparisons between the curves recorded were made but also integral sensitivity indicators were used. The subject matter of this work may be reasonably expected to arouse interest both in specialists working in the field of mechatronic control systems in motor vehicles and in the researchers who are engaged in exploring the problem of structural sensitivity of nonlinear dynamic systems.
\end{abstract}

Keywords: active safety, active steering system, lane change manoeuvre, computer modelling and simulation, effective reference model, time-optimal "bang-bang" control, Kalman regulator.

\section{INTRODUCTION}

The lane change is one of the elementary manoeuvres, which may be used to compose manoeuvres of a more complex sequential structure, e.g. overtaking or obstacle avoidance. The issue of modelling and simulation of the lane-change manoeuvre is dealt with in many scientific publications, both those where the road traffic is discussed "at the macro level" (e.g. [1]), where the analysis is chiefly dedicated to the vehicle flow, and those where the processes of lateral dynamics of the vehicle steered are described in great detail "at the micro level" (e.g. [2]). The former approach is typical for the analysis of transport systems (e.g. in the context of optimizing specific road infrastructure solutions). The later approach, in turn, is typical for the analysis of active safety of a single vehicle (e.g. in the context of optimizing vehicle construction solutions and providing the vehicle with mechatronic systems). The work presented here concerns the latter field of research activities.

The lane change is often the only practical way out of a dramatic situation, when an obstacle has suddenly sprung up in front of a vehicle, too close for the vehicle to be successfully braked. Such a manoeuvre is extremely dangerous, especially when the vehicle 
is driven in difficult road conditions, on a slippery and narrow carriageway. At higher speeds, a violent lane change may result in a wheel lift-off or even vehicle rollover. Situations of this kind also happen in cities on arterial roads. Therefore, the lane change process as a subject of the research work presented here is perceived as important for the issues related to the safety of urban traffic.

With the development of modern technologies, present-day motor vehicles are provided with increasingly perfect driver assistance systems, facilitating the process of driving [3]. The vision of a totally automated vehicle, capable of autonomous performing many manoeuvres, comes closer and closer, too [4]. This applies not only to automatically controlled vehicles moving in urban traffic at low speeds, where the issues related to vehicle dynamics are not particularly important, but also to vehicles driven with high speeds, where the role of dynamics is essential.

The automatization of the lane-change manoeuvre with vehicle's "lateral dynamics" being taken into account is considered fundamental for the automatization of vehicle steering; it is also a subject matter of numerous scientific publications. In such works, various issues are addressed, which may be grouped in two basic research lines. The first one is related to the vehicle steering in an open-loop system, i.e. according to a precisely predefined course of changing the steering wheel angle. This line includes mathematic modelling, identification, and simulation of vehicle motion at rapid turns of steered wheels (e.g. [5]) as well as, which is particularly important, the analysis of parametric and structural sensitivity of the models used (e.g. [6]). The development of an adequate mathematical model describing the dynamics of motion of a vehicle moving with a high speed and subjected to a rapid change in the steering angle is a prerequisite for the undertaking of research on the steering process in a closed-loop system, covering not only the vehicle but also a controller (a driver or an automatic device) that performs the lane-change manoeuvre in a closed-loop system, i.e. a system with feedback. This is the second research line; it includes a number of detailed problems, such as defining the desired vehicle trajectory (e.g. [7]) or synthesis of a model of the driver or regulators (e.g. [2]). In the modern approach, an increasingly important role is played by the up-to-date controller designing methods, inclusive of those referring to the optimal control theory (e.g. [8]). A more detailed introduction to the closed-loop system control issues may be found in authors' publications [9], [10].

Within a project implemented by the authors, extensive research and development works were done on the automatization and optimization (in terms of time and accuracy) of controlling the lane-change manoeuvre in emergency situations with a collision risk. The works were reported in a number of authors' publications (e.g. [9]-[13]). In this paper, the concepts of models and systems have been described, with attention being focused on interesting and non-published results of simulation tests. Following the introduction in Section 1, a concept of a system of automatic controlling of the lane-change manoeuvre, developed with the use of a simplified reference mathematic model of lateral dynamics of a motor vehicle, has been presented in Section 2. In Section 3, the simulation test method used has been described, where an extensive model of a two-axle motor truck was used as a virtual steered object. The selection of such a vehicle model with rather hardly predictable dynamic behaviour made it possible to analyse, within a wider range, the sensitivity of the control system to changes in the object parameters. Section 4 presents, as an example, representative simulation test results related to difficult conditions of operation of a vehicle controlled in an open-loop and closed-loop system. The tests had the nature of sensitivity examinations, because they were carried out to compare the response curves obtained for different values of model parameters and the differences were assessed with the use of integral indicators. The test results show the complexity of the dynamic properties of 
the controlled vehicle and confirm the reasonability of the automatic control solutions adopted.

\section{CONCEPT OF AUTOMATIC CONTROL OF THE LANE-CHANGE PROCESS}

In this study, a motor vehicle provided with an automatic dodging system is considered. In the analysis, an assumption has been made that the vehicle moves with a significant speed and suddenly an obstacle springs up in front of it. The driver or the Automatic Cruise Control (ACC) system applies brakes. If a collision cannot be avoided by braking and the automatic dodging system may be used, the lane-change control system is automatically operated by means of an active steering system. In result of the system operation, the vehicle dodges the obstacle with a preset speed resulting from the braking process. The analysis of the situation and the instant of operating the steering system constitute a complicated optimization problem, which is not covered herein. The scope of this analysis is narrowed to controlling the lane-change process.

The plane vehicle motion in the lane-change process is described by two variables: position of the centre of vehicle mass relative to the road centreline $\mathrm{Y}(\mathrm{t})$ and angular position of the vehicle body relative to the road centreline (yaw angle) $\psi(\mathrm{t})$. According to drivers' experience, as well as to the control theory, the steering wheel angle curve minimizing the manoeuvre time should be close to the "bang-bang" curve (according to the terminology used in the theory of time-optimal systems) and the control process may be decomposed into two phases, i.e. transposition and angular stabilization (Fig. 1).

\section{Lane change process}
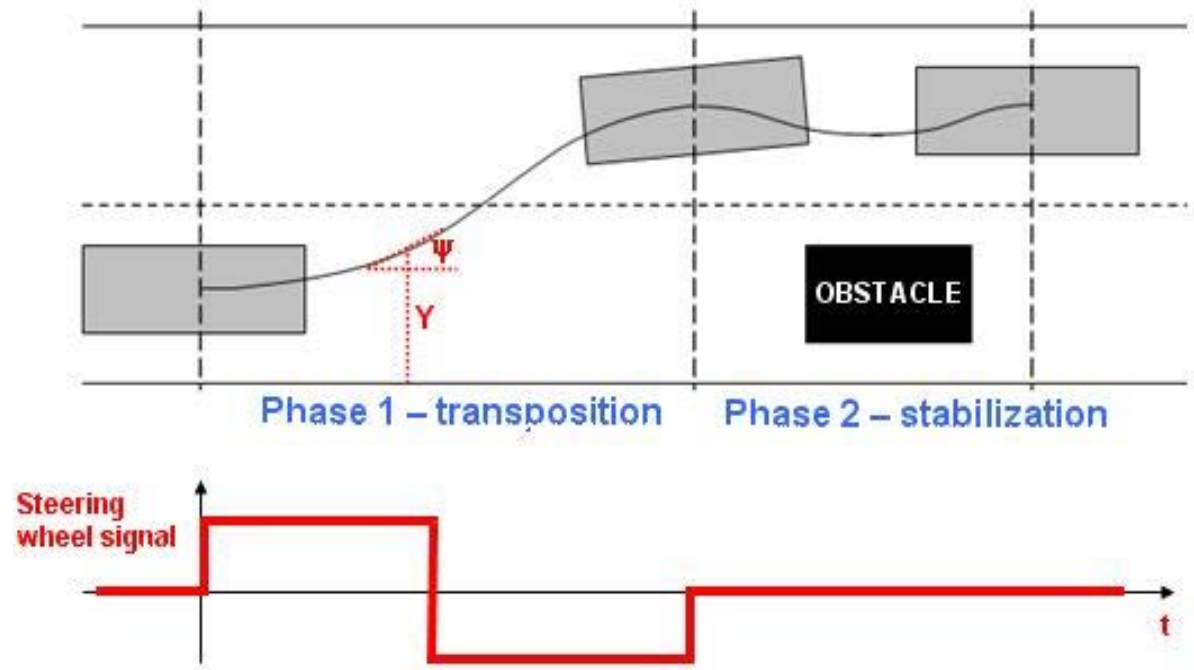

Figure 1: The concept of "bang-bang" type steering and time decomposition of lane change control. 
The initial reference model used in the automatic control algorithm was developed from the known "bicycle model" of the lateral dynamics of a motor vehicle [14]. In the classic approach, the bicycle model consists of two linear differential equations of motion representing the time histories of the linear lateral and angular velocities $U(t)$ and $\Omega(t)$, respectively, of the vehicle body solid in a local coordinate system $(\mathrm{x}, \mathrm{y})$ attached to it, in response to a time history of the steering angle $\delta(\mathrm{t})$ being applied as an input. For the motion to be described in the global coordinate system $(\mathrm{X}, \mathrm{Y})$, appropriate trigonometric transformations must be made. There are seven parameters in this model, i.e. $\mathrm{V}, \mathrm{m}, \mathrm{I}_{\mathrm{z}}, \mathrm{k}_{\mathrm{A}}, \mathrm{k}_{\mathrm{B}}$, $\mathrm{L}_{\mathrm{A}}$, and $\mathrm{L}_{\mathrm{B}}$, defined by the construction and conditions of operation of the vehicle. The initial reference model has been presented in detail in Fig. 2.

For small and short-duration steering angle changes $\delta(t)$ (this condition being met by the control signals that occur during the obstacle avoidance manoeuvre), the transformation equations may be linearized. Thus, a linear dynamic model is obtained, describing the $Y(t)$ and $\psi(\mathrm{t})$ curves in the global coordinate system. In this model, all the relations being linear may be subjected to the Laplace transformation and appropriate transmittances $\mathrm{G}_{\mathrm{Y} \delta}(\mathrm{s})$ and $\mathrm{G}_{\psi \delta}(\mathrm{s})$ may be obtained that would define the relations between transforms $\mathrm{Y}(\mathrm{s})$ and $\psi(\mathrm{s})$ of the output time functions and transform $\delta(s)$ of the input signal. In the transmittances, there are amplification and damping coefficients, characteristic frequencies, and time constants, whose values directly depend on parameters $\mathrm{V}, \mathrm{m}, \mathrm{I}_{\mathrm{z}}, \mathrm{k}_{\mathrm{A}}, \mathrm{k}_{\mathrm{B}}, \mathrm{L}_{\mathrm{A}}$, and $\mathrm{L}_{\mathrm{B}}$.

In this study, the transmittances $G_{Y \delta}(s)$ and $G_{\psi \delta}(s)$ provided a basis for analysing the behaviour of a vehicle, which moved with a constant speed $\mathrm{V}$ on an even homogenous road and was suddenly subjected to a rapid turn of its steering wheels, made once to the one side and then to the other side, i.e. according to the "bang-bang" pattern. Since the assumed
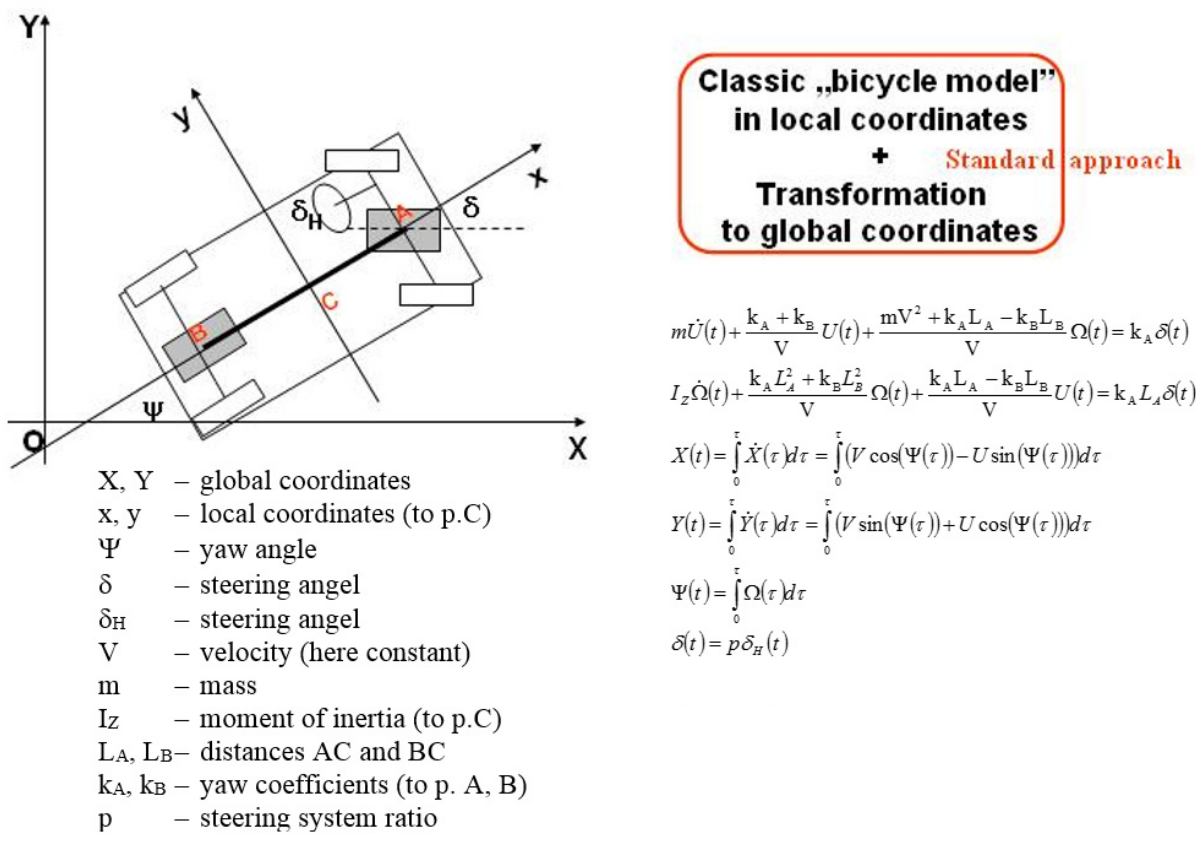

$m \dot{U}(t)+\frac{\mathrm{k}_{\mathrm{A}}+\mathrm{k}_{\mathrm{B}}}{\mathrm{V}} U(t)+\frac{\mathrm{mV}^{2}+\mathrm{k}_{\mathrm{A}} \mathrm{L}_{\mathrm{A}}-\mathrm{k}_{\mathrm{B}} \mathrm{L}_{\mathrm{B}}}{\mathrm{V}} \Omega(t)=\mathrm{k}_{\mathrm{A}} \delta(t)$

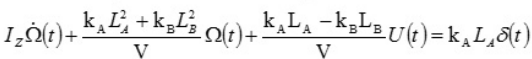

$X(t)=\int_{0}^{\tau} \dot{X}(\tau) d \tau=\int_{0}^{\tau}(V \cos (\Psi(\tau))-U \sin (\Psi(\tau))) d \tau$

$Y(t)=\int_{0}^{\tau} \dot{Y}(\tau) d \tau=\int_{0}^{\tau}(V \sin (\Psi(\tau))+U \cos (\Psi(\tau))) d \tau$

$\Psi(t)=\int_{0}^{\tau} \Omega(\tau) d \tau$

$\delta(t)=p \delta_{H}(t)$

Figure 2: Initial reference model describing the vehicle motion in the local and global coordinate systems. 
analytic form of the input $\delta(\mathrm{t})$ (and its transform $\delta(\mathrm{s})$ as well as the transmittances $\mathrm{G}_{\mathrm{Y} \delta}(\mathrm{s})$ and $\left.\mathrm{G}_{\psi \delta}(\mathrm{s})\right)$ were known, the $\mathrm{Y}(\mathrm{t})$ and $\psi(\mathrm{t})$ curves could be analysed with the use of boundary relations, known from the operational calculus, which explain why a steady state of the process (with a given displacement value $\mathrm{Y}=\mathrm{Y}_{0}$ and a zero vehicle yaw angle $\psi=0$ ) is reached at a steering input of the "bang-bang" type. This has been depicted in Fig. 3, where the transmittances $\mathrm{G}_{Y \delta}(\mathrm{s})$ and $\mathrm{G}_{\psi \delta}(\mathrm{s})$ have a reduced form, subsequently used to synthesize the control algorithm. The reduced model was used here not only to determine the analytical form of the reference signals $Y_{R}(t)$ and $\psi_{R}(t)$ but also to define the optimum structures of the regulators correcting the control signal $\delta_{\mathrm{R}}(\mathrm{t})$.

The lane-change controller (Fig. 4) consists of a generator of three reference signals (steering wheel angle signal $\delta_{H R}(t)$, lateral displacement signal $Y_{R}(t)$, yaw angle signal $\psi_{R}(t)$ ), and two regulation loops with Kalman regulators which correct the steering wheel angle signal $\delta_{\mathrm{H}}(\mathrm{t})$ in order to minimize errors between the reference signals (set point signals) and the measured (actual) signals describing vehicle motion. The regulation circuits are activated in succession: firstly - for transposition, and then - for stabilization.

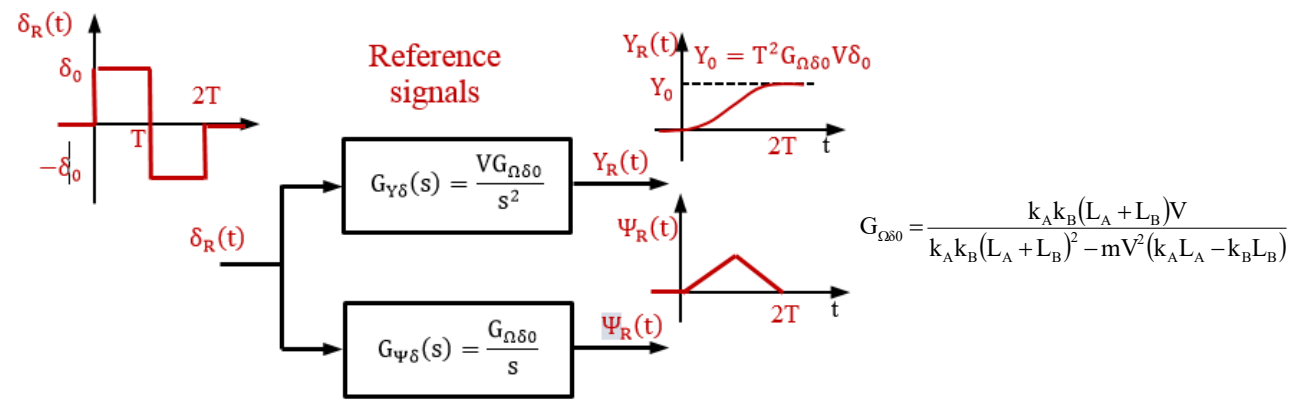

Figure 3: Reduced transmittance-based reference model describing the vehicle motion in the global coordinate system for the "bang-bang" type control.

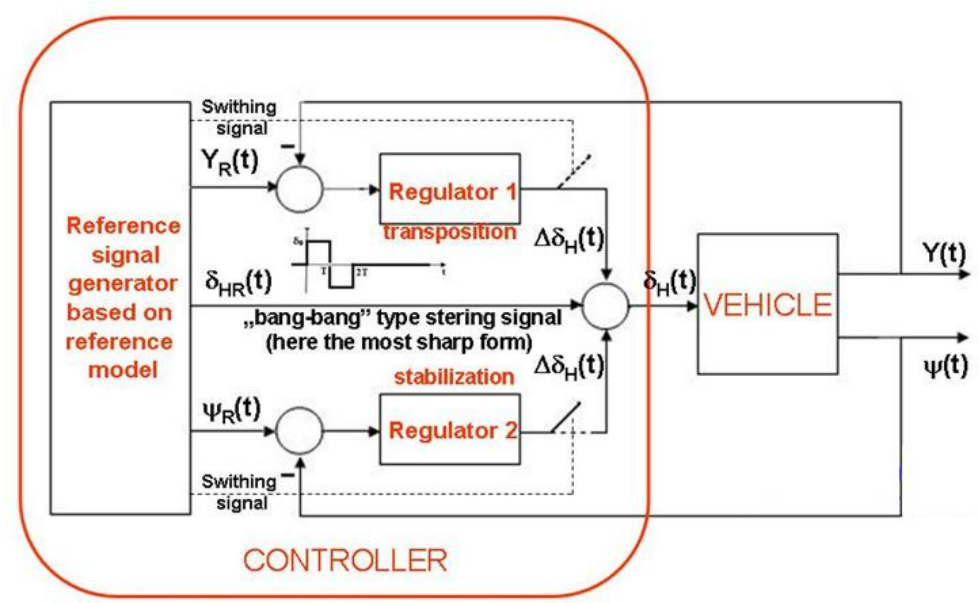

Figure 4: The concept of lane change control system. 
The controller algorithm requires entering the actual values of several operation parameters $(\mathrm{V}, \mathrm{m}$, etc.) of the car, as well as two parameters of the lane change manoeuvre $\left(\mathrm{Y}_{0}, \mathrm{~T}\right)$. An identification procedure of the operation parameters has to be carried out before the lane change process. Of course, this requires that the obstacle avoidance system should be provided with appropriate detectors. It should be noted, however, that in a modern motor vehicle, a part of the necessary information might be obtained through the Controller Area Network (CAN) system from other mechatronic active safety systems.

The values of amplitude $\delta_{0}$ and duration time $\mathrm{T}$ of the reference control signal $\delta_{\mathrm{HR}(\mathrm{t})}$ generated cannot be unequivocally determined. In accordance with the reduced reference model, the same $Y_{0}$ displacement effect may be obtained when input signals with low $\delta_{0}$ and high T values or high $\delta_{0}$ and low T values are applied. The lane-change process duration time cannot be minimized by unlimitedly raising the control signal amplitude because this may result in process destabilization. For the analytical relation between $\mathrm{Y}_{0}$ and $\delta_{0}$ and $\mathrm{T}$ to hold, after all the model linearization assumptions must be true; hence, in practice, the instantaneous values of the derivatives of functions $\mathrm{Y}(\mathrm{t})$ and $\psi(\mathrm{t})$ must be within acceptability limits. These peak values may be determined in a simulation process.

The determination of parameters of the Kalman regulators is based on the transmittances taken from the reduced reference model and specified in the block diagram shown in Fig. 3. This has been described in detail in authors' publications [9], [10]. The mathematical formulas defining the parameters of these regulators (of the proportional-derivative (PD) type in this case) require that the amplification coefficient $\mathrm{G}_{\Omega \delta 0}$, which directly depends on the reference model parameters (V, m, etc.), should be known. Since a real steered object is characterized by much more complicated dynamics than the dynamics represented in the reduced model, the selection of regulator parameters must be confirmed by simulation tests.

\section{CONCEPT OF THE SIMULATION RESEARCH}

The lane-change process control method developed had to be thoroughly tested. With this objective in view, a series of simulations were carried out, where a "complex model" of the dynamics of a real vehicle [11], [15], extended and experimentally verified, was used as a virtual steered object. The simulation tests were carried out in an open-loop system and a closed-loop system (Fig. 5). As the steered object, a two-axle motor truck STAR 1142 of medium load capacity was used.

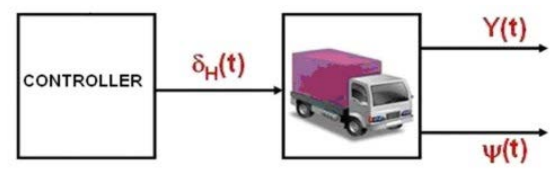

Open-loop system

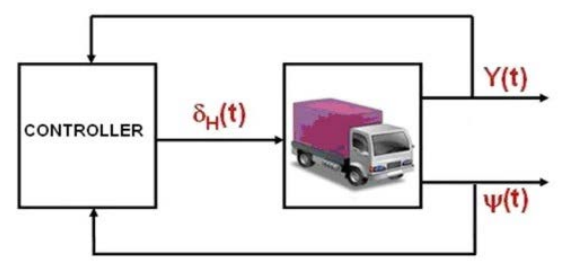

Closed-loop system

Figure 5: The concept of simulation research. 
The physical model of the STAR 1142 vehicle is a three-dimensional discrete dynamic system, in which all the major features of the real steered object are taken into account. It consists of seven rigid bodies (vehicle body, front axle, rear axle, and four road wheels), linked with each other by spring and damping elements having non-linear characteristics and representing the suspension system and wheel tyres. The model has 20 degrees of freedom, where the vehicle body solid has six of them, the front and rear axle beams have four degrees of freedom each, and the front and rear wheels have two and one degrees of freedom each, respectively (the rear wheels being assumed as dual wheels).

The tyre-road interaction has been described with using the known Dugoff model as a basis and with taking into account the spring and damping tyre characteristics in the radial, lateral, and circumferential direction. The tyre-road interaction model developed within this work makes it possible to simulate the vehicle motion in the conditions of full tyre slip, allows for different tyre-road adhesion coefficient values on both vehicle sides, and handles the wheel lift-off effect. The wheel driving and braking model includes simplified models of conventional ABS, ASR, and ESP systems.

The model of the vehicle steering system has been built with taking into account the geometry, kinematics, as well as spring and damping characteristics of the suspension system. In the conventional STAR 1142 steering system, a planetary gear and an electric motor have been added, thanks to which the unit may function as an active servo, digitally controlled (e.g. in accordance with the controller algorithm proposed, where the current vehicle position measured, feedback, and regulators may be made use of). In the model of the steering system treated as a servo, not only the spring and damping effects but also the dynamic effects caused by system operation inertia are allowed for.

As it can be seen, the "complex model" goes far beyond the simplifying assumptions adopted in the reference model, not only in the reduced version but also in the original version of the latter (the "bicycle model").

The computational model prepared requires the loading of more than 200 parameters. Their values were determined from design specifications of the STAR 1142 motor truck and by experimental identification. A noteworthy feature of the vehicle model prepared is the fact that it has passed a very extensive and thorough experimental verification during road tests in an open-loop system, i.e. with predefined input control signals. The road tests were carried out in both steady-state conditions (uniform motion along a circle) and transient conditions (after a rapid turn of the steering wheel during straightforward drive, with applying brakes of selected or all vehicle wheels). During the tests, time histories of several dozens of quantities, describing the parameters of motion of individual vehicle solids, were measured. In result of careful tuning of model parameters, good conformity has been obtained between the calculation and experimental test results. This has provided grounds for a statement that the vehicle model prepared adequately describes the vehicle properties in steady and transient conditions of motion and, in consequence, it may be used as a virtual steered object for the simulation of vehicle motion in various, even difficult, traffic conditions and situations. In particular, it may serve as a virtual steered object for the simulation of a lane-change process, run with the use of an automatic controller.

The "complex model" was used for preliminary simulation tests in an open-loop system, in steady-state and transient conditions, with making use of the ISO test procedures. The tests were carried out for a few variants of the vehicle load (vehicle unladen, half-laden, and fully laden, with low and high position of the centre of the sprung mass), different road surface types (with the adhesion coefficient value within the range of $\mu=0.1-0.7$ ), and different driving speeds. Each of the tests in specific predefined conditions of motion was repeated several times, with trying to bring the vehicle motion to the state of instability. The tests made 
it possible to define the scenarios of loss of vehicle stability and to determine the critical process parameter values at which the instability occurred.

Table 1 presents, in a synthetic form, example results of steady-state circular driving tests with a constant steering wheel angle, showing the reasons for a stability loss, for different vehicle loads and road surface types. Changes in the motor truck load considerably affected the vehicle behaviour. The unladen vehicle lost its directional stability in result of the loss of tyre grip at the rear wheels regardless of the road surface type. In turn, the fully laden vehicle with the low position of the centre of its sprung mass lost its directional stability on every road surface type due to the loss of tyre grip at the front wheels. The half-laden vehicle, with the centre of its sprung mass being in the low position, lost its directional stability in result of the loss of tyre grip at the rear wheels when being driven on slippery road surfaces; in the case of road surfaces with higher adhesion coefficients, the stability loss was caused by the loss of front wheel tyre grip. The higher position of the centre of the sprung mass, combined with higher tyre-road adhesion coefficients, resulted in the fact that the vehicle lost its stability due to the unloaded vehicle wheels being lifted off rather than to a tyre slip. The cited fragments of preliminary test reports show that the dynamics of motion of a motor vehicle is much complicated.

Table 1: Reasons for the vehicle stability loss (ay - maximum lateral acceleration).

\begin{tabular}{|c|c|c|c|c|c|}
\hline \multirow[b]{2}{*}{$\mu$} & \multirow[b]{2}{*}{ Vehicle unladen } & \multicolumn{2}{|c|}{ Vehicle half-laden } & \multicolumn{2}{|c|}{ Vehicle fully laden } \\
\hline & & $\begin{array}{c}\text { Low centre of } \\
\text { mass }\end{array}$ & $\begin{array}{c}\text { High centre of } \\
\text { mass }\end{array}$ & $\begin{array}{c}\text { Low centre of } \\
\text { mass }\end{array}$ & $\begin{array}{c}\text { High centre of } \\
\text { mass }\end{array}$ \\
\hline 0.1 & $\begin{array}{c}\text { Full slip of rear } \\
\text { axle wheels } \\
a_{y}=1.12 \mathrm{~m} / \mathrm{s}^{2}\end{array}$ & $\begin{array}{c}\text { Full slip of rear } \\
\text { axle wheels } \\
a_{\mathrm{y}}=1.12 \mathrm{~m} / \mathrm{s}^{2}\end{array}$ & $\begin{array}{c}\text { Full slip of rear } \\
\text { axle wheels } \\
a_{\mathrm{y}}=1.16 \mathrm{~m} / \mathrm{s}^{2}\end{array}$ & $\begin{array}{c}\text { Full slip of } \\
\text { front axle } \\
\text { wheels } \\
\mathrm{a}_{\mathrm{y}}=1.15 \mathrm{~m} / \mathrm{s}^{2}\end{array}$ & $\begin{array}{c}\text { Full slip of front } \\
\text { axle wheels } \\
a_{\mathrm{y}}=1.16 \mathrm{~m} / \mathrm{s}^{2}\end{array}$ \\
\hline 0.2 & $\begin{array}{l}\text { Full slip of rear } \\
\text { axle wheels } \\
a_{y}=2.15 \mathrm{~m} / \mathrm{s}^{2}\end{array}$ & $\begin{array}{c}\text { Full slip of rear } \\
\text { axle wheels } \\
a_{y}=2.29 \mathrm{~m} / \mathrm{s}^{2}\end{array}$ & $\begin{array}{c}\text { Full slip of rear } \\
\text { axle wheels } \\
a_{y}=2.29 \mathrm{~m} / \mathrm{s}^{2}\end{array}$ & $\begin{array}{c}\text { Full slip of } \\
\text { front axle } \\
\text { wheels } \\
\mathrm{a}_{\mathrm{y}}=2.23 \mathrm{~m} / \mathrm{s}^{2}\end{array}$ & $\begin{array}{l}\text { Full slip of front } \\
\text { axle wheels } \\
a_{\mathrm{y}}=2.28 \mathrm{~m} / \mathrm{s}^{2}\end{array}$ \\
\hline 0.3 & $\begin{array}{c}\text { Full slip of rear } \\
\text { axle wheels } \\
a_{y}=3.16 \mathrm{~m} / \mathrm{s}^{2}\end{array}$ & $\begin{array}{l}\text { Full slip of } \\
\text { front axle } \\
\text { wheels } \\
\text { ay }=3.27 \mathrm{~m} / \mathrm{s} 2\end{array}$ & $\begin{array}{c}\text { Full slip of rear } \\
\text { axle wheels } \\
a_{\mathrm{y}}=3.30 \mathrm{~m} / \mathrm{s}^{2}\end{array}$ & $\begin{array}{l}\text { Full slip of } \\
\text { front axle } \\
\text { wheels } \\
a_{\mathrm{y}}=3.24 \mathrm{~m} / \mathrm{s}^{2}\end{array}$ & $\begin{array}{c}\text { Full slip of front } \\
\text { axle wheels } \\
a_{\mathrm{y}}=3.35 \mathrm{~m} / \mathrm{s}^{2}\end{array}$ \\
\hline 0.4 & $\begin{array}{c}\text { Full slip of rear } \\
\text { axle wheels } \\
a_{y}=4.18 \mathrm{~m} / \mathrm{s}^{2}\end{array}$ & $\begin{array}{l}\text { Full slip of } \\
\text { front axle } \\
\text { wheels } \\
a_{\mathrm{y}}=4.23 \mathrm{~m} / \mathrm{s}^{2}\end{array}$ & $\begin{array}{c}\text { Rear wheel lift- } \\
\text { off } \\
\mathrm{a}_{\mathrm{y}}=4.28 \mathrm{~m} / \mathrm{s}^{2}\end{array}$ & $\begin{array}{l}\text { Full slip of } \\
\text { front axle } \\
\text { wheels } \\
\mathrm{a}_{\mathrm{y}}=4.20 \mathrm{~m} / \mathrm{s}^{2}\end{array}$ & $\begin{array}{c}\text { Full slip of front } \\
\text { axle wheels } \\
a_{\mathrm{y}}=4.25 \mathrm{~m} / \mathrm{s}^{2}\end{array}$ \\
\hline 0.5 & $\begin{array}{c}\text { Full slip of rear } \\
\text { axle wheels } \\
a_{y}=5.00 \mathrm{~m} / \mathrm{s}^{2}\end{array}$ & $\begin{array}{l}\text { Full slip of } \\
\text { front axle } \\
\text { wheels } \\
\mathrm{a}_{\mathrm{y}}=5.10 \mathrm{~m} / \mathrm{s}^{2}\end{array}$ & $\begin{array}{c}\text { Rear wheel lift- } \\
\text { off } \\
a_{\mathrm{y}}=4.78 \mathrm{~m} / \mathrm{s}^{2}\end{array}$ & $\begin{array}{l}\text { Full slip of } \\
\text { front axle } \\
\text { wheels } \\
a_{y}=5.11 \mathrm{~m} / \mathrm{s}^{2}\end{array}$ & $\begin{array}{c}\text { Rear wheel lift- } \\
\text { off } \\
\mathrm{a}_{\mathrm{y}}=4.97 \mathrm{~m} / \mathrm{s}^{2}\end{array}$ \\
\hline 0.6 & $\begin{array}{c}\text { Full slip of rear } \\
\text { axle wheels } \\
a_{\mathrm{y}}=5.88 \mathrm{~m} / \mathrm{s}^{2}\end{array}$ & $\begin{array}{c}\text { Full slip of } \\
\text { front axle } \\
\text { wheels } \\
\mathrm{a}_{\mathrm{y}}=6.00 \mathrm{~m} / \mathrm{s}^{2}\end{array}$ & $\begin{array}{c}\text { Rear wheel lift- } \\
\text { off } \\
\mathrm{a}_{\mathrm{y}}=4.80 \mathrm{~m} / \mathrm{s}^{2}\end{array}$ & $\begin{array}{c}\text { Full slip of } \\
\text { front axle } \\
\text { wheels } \\
\mathrm{a}_{\mathrm{y}}=6.00 \mathrm{~m} / \mathrm{s}^{2}\end{array}$ & $\begin{array}{c}\text { Rear wheel lift- } \\
\text { off } \\
\mathrm{a}_{\mathrm{y}}=5.00 \mathrm{~m} / \mathrm{s}^{2}\end{array}$ \\
\hline 0.7 & $\begin{array}{c}\text { Full slip of rear } \\
\text { axle wheels } \\
a_{\mathrm{y}}=6.60 \mathrm{~m} / \mathrm{s}^{2}\end{array}$ & $\begin{array}{c}\text { Full slip of } \\
\text { front axle } \\
\text { wheels } \\
a_{\mathrm{y}}=6.75 \mathrm{~m} / \mathrm{s}^{2}\end{array}$ & $\begin{array}{c}\text { Rear wheel lift- } \\
\text { off } \\
\mathrm{a}_{\mathrm{y}}=4.80 \mathrm{~m} / \mathrm{s}^{2}\end{array}$ & $\begin{array}{c}\text { Full slip of } \\
\text { front axle } \\
\text { wheels } \\
a_{\mathrm{y}}=6.91 \mathrm{~m} / \mathrm{s}^{2}\end{array}$ & $\begin{array}{c}\text { Rear wheel lift- } \\
\text { off } \\
\mathrm{a}_{\mathrm{y}}=5.00 \mathrm{~m} / \mathrm{s}^{2}\end{array}$ \\
\hline
\end{tabular}




\section{SIMULATION RESEARCH ON THE CONTROLLED \\ LANE-CHANGE PROCESS}

The simulation tests of the controlled lane-change process were carried out in an open-loop and closed-loop system, in accordance with the schematic diagrams shown in Fig. 5. In the tests, the controller model based on the simplified reduced reference model controlled the extended and experimentally verified model of the STAR 1142 motor truck, treated as a virtual object. In the open-loop system, the controller just generated a reference steering wheel angle control signal based on the reduced reference model (Fig. 3). In the closed-loop system, the controller defined a control signal corrected by Kalman regulators, as illustrated in the schematic diagram of the full controller version shown in Fig. 4. The repeating of the tests with using both structures was aimed at verifying the favourable impact (if the control system is correctly designed), known from the control theory and practical experience, of negative feedbacks and regulators on the control dynamics.

The simulation tests were repeated for many variants of parameters of the "complex model" of vehicle dynamics, including different options of intentionally introduced disturbances to the signals measured and various inaccuracies in parameter estimations. The objective was to verify the sensitivity of the control system to various factors left out of account in the construction of the reference model, especially those that actually manifest themselves only in the "complex model" (e.g. a change from understeering to oversteering vehicle characteristics or the wheel lift-off effect).

In some cases, especially when the assessment by comparing the response curves was difficult, integral sensitivity indexes were also determined in the simulation calculations for the sake of objectivity in the sensitivity estimation. This idea has been illustrated in the schematic diagram shown in Fig. 6.

Results of a number of tests can also be found in other authors' publications [9]-[13]. In this paper, some non-published results of selected simulation tests have been presented in Fig. 7.

Here, an assumption has been made that the virtual object (fully laden STAR 1142 motor truck with a mass of $\mathrm{m}=11300 \mathrm{~kg}$ ) moving with a constant speed $\mathrm{V}$ on a straight, even, homogenous, and very slippery road, with an adhesion coefficient of $\mu=0.2$, performs a lanechange manoeuvre with a lateral displacement by $\mathrm{Y}_{0}=3 \mathrm{~m}$ within as short a time as possible. Apart from the assessment of the impact of regulators on the course of the process, the sensibility of the control system to the inaccuracy of identification of the tyre-road adhesion coefficient, and for various vehicle speeds at that, is examined here. In the example under analysis, the $\mu$ coefficient value is overestimated by $20 \%$ in relation to the actual value appearing in the "accurate" ("nominal") model (i.e. it is equal to 0.24 ).

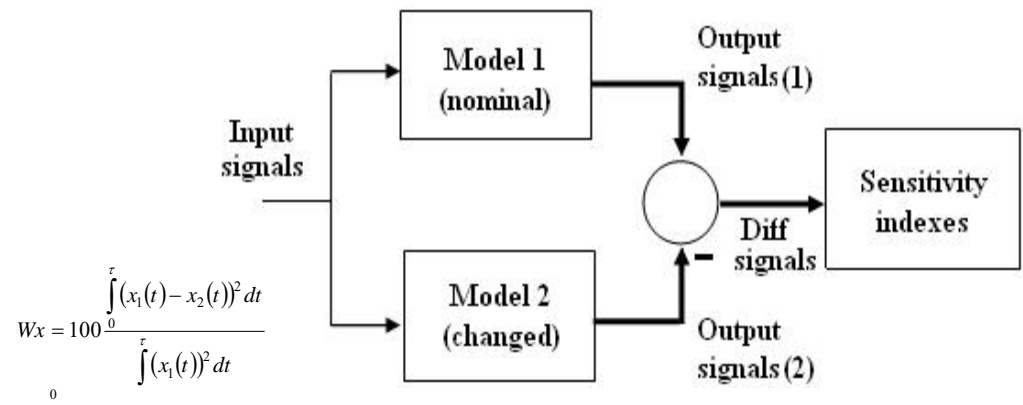

Figure 6: Schematic diagram of determining the sensitivity indexes. 
Open system
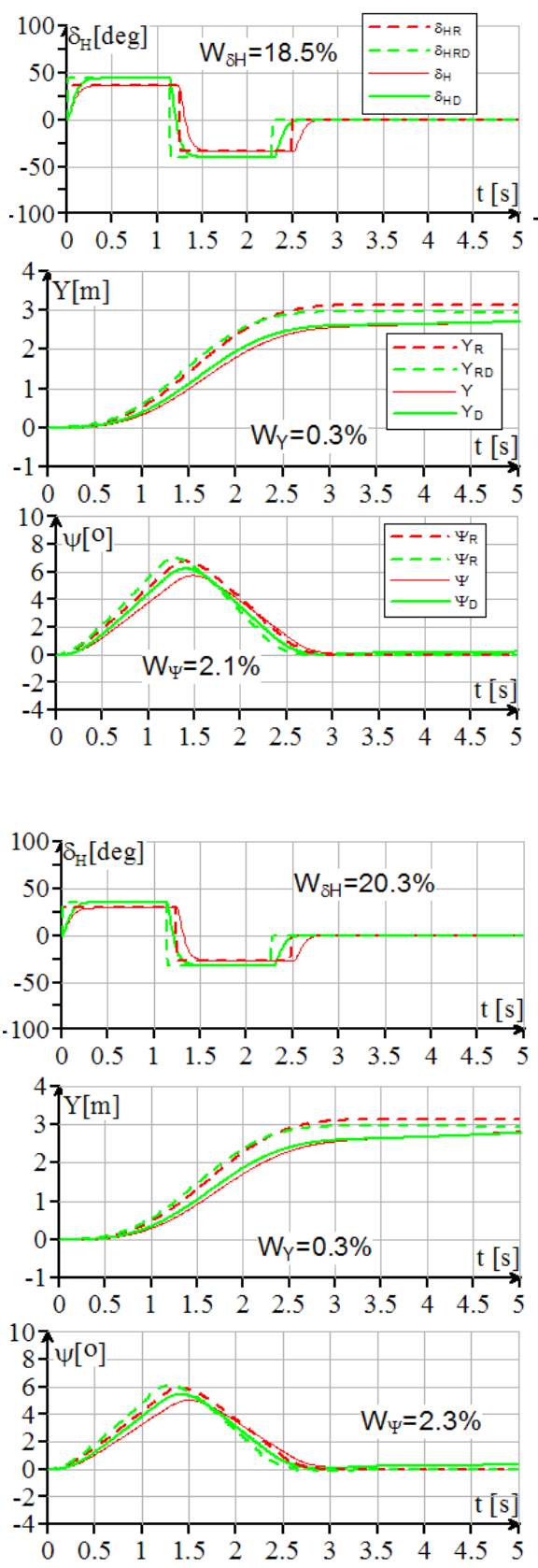

Closed system

a) $\mathrm{V}=70 \mathrm{~km} / \mathrm{h}$
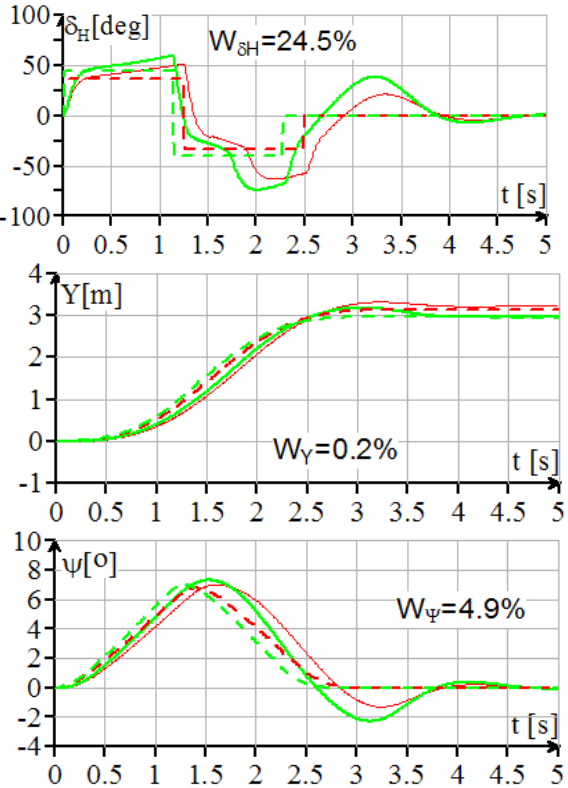

b) $\mathrm{V}=80 \mathrm{~km} / \mathrm{h}$
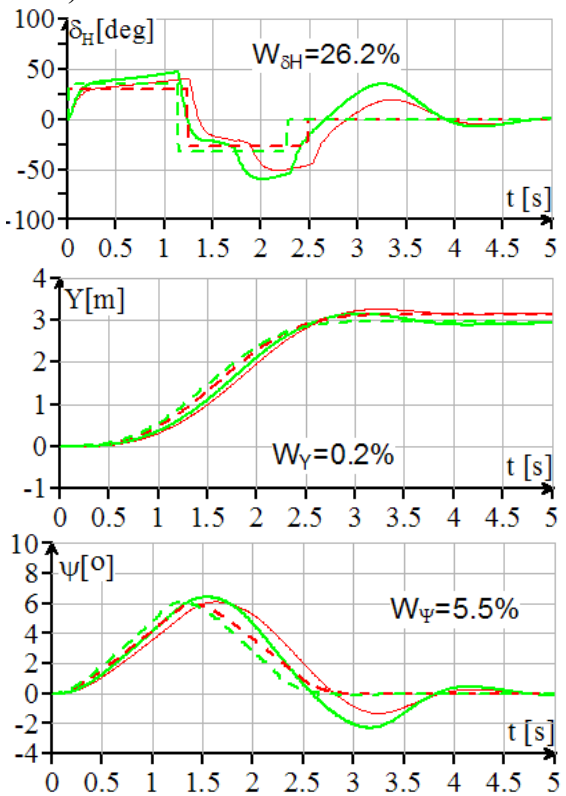

Figure 7: Example simulation results of lane change process in open-loop and closed-loop system. Notation used: red line - waveforms for nominal model, green line waveforms for changed model, dashed line - reference waveforms, solid line real waveforms. 
The simulation tests presented here were carried out for two actual values of vehicle speed V, i.e. $19.44 \mathrm{~m} / \mathrm{s}(70 \mathrm{~km} / \mathrm{h})$ and $22.22 \mathrm{~m} / \mathrm{s}(80 \mathrm{~km} / \mathrm{h})$, and were repeated for the open-loop and closed-loop control system structure. The calculation results have the form of curves representing time histories $\delta_{\mathrm{H}}(\mathrm{t}), \mathrm{Y}(\mathrm{t})$ and $\psi(\mathrm{t})$ as well as values of integral indexes $\mathrm{W}_{\delta}, \mathrm{W}_{\mathrm{Y}}$, and $\mathrm{W}_{\psi}$. According to the terminology used in Fig. 6, the "nominal model" (Model 1) is a model without the error of measurement of adhesion coefficient $\mu$ and the "changed model" (Model 2) is a model where the controller in the reference model is based on parameters corresponding to the $\mu$ values overestimated by $20 \%$ (i.e. $\mu=0.24$ ).

\section{RECAPITULATION AND CONCLUSIONS}

The paper provides basic information on the algorithm governing the operation of the automatic controller of the lane-change process as well as example results of simulation tests of motion of the STAR 1142 motor truck, performed in an open-loop system (without regulators) and in a closed-loop system (with regulators) for different variants of model parameters. The effects of changes in the model parameters were assessed by comparing the response curves and, in addition to that, with the use of integral sensitivity indexes.

The simulation results presented confirm the need of using regulators to correct the "bangbang" reference control signal generated by the system. Without the regulators, the vehicle would not achieve the zero value of derivative of the $\psi(t)$ signal, i.e. it would depart from the rectilinear path. With the regulators being on, the vehicle path is stabilized almost immediately.

The simulation results show that even at poor accuracy of measurement of parameter $\mu$, the control of vehicle motion can result in a satisfactory effect of the lane-change process.

The simulation tests of the lane-change process, where the automatic controller is based on a simple reduced reference model and the virtual steered object is an extended non-linear model of a two-axle motor truck, seem to confirm correctness of the control system concept adopted.

\section{REFERENCES}

[1] Shiomi, Y., Taniguchi, T., Uno, N., Shimamoto, H. \& Nakamura, T., Simulating Lane-Changing Dynamics towards Lane-Flow Equilibrium Based on Multi-Lane First Order Traffic Flow Model. Transportation Research Procedia 6, 2015.

[2] Hatipoglu, C., Özgüner, Ü., Keith, A., \& Redmil, K.A., Automated Lane Change Controller Design. IEEE Transactions on Intelligent Transportation Systems, 4(1), Mar 2003.

[3] STARDUST: Critical Analysis of ADAS/AVG Options to 2010. European Commission Fifth Framework Programme Energy, Environment and Sustainable Development Programme Key Action 4: City of Tomorrow and Cultural Heritage (available on the Internet).

[4] Gordon, T.J. \& Lidberg, M., Automated driving and autonomous functions on road vehicles. Vehicle System Dynamics, 53(7), 2015.

[5] Peng, Y. \& Yang, X., Comparison of Various Double-Lane Change Manoeuvre Specifications. Vehicle System Dynamics, 50(7), Jul. 2012.

[6] Więckowski, D. \& Żardecki, D., Influence of freeplay and friction in steering system on double lane change manoeuvre. Logistyka, 4/2010.

[7] Bevan, G. P., Gollee, H. \& O'Reilly, J., Trajectory generation for road vehicle obstacle avoidance using convex optimization. Proceedings of the Institute of Mechanical Engineers, Part D: Journal of Automobile Engineering, 224(4), 2010. 
[8] Sharp, R. S. \& Peng, H., Vehicle dynamics applications of optimal control theory. Vehicle System Dynamics, 49(7), Jul. 2011.

[9] Gidlewski, M. \& Żardecki, D., Automatic control of steering system during lane change. Proceedings of 24th ESV'2015 Conference in Gothenburg, Sweden, available on the Internet.

[10] Gidlewski, M., Jankowski, K., Muszyński, A. \& Żardecki, D., Vehicle Lane Change Automation with Active Steering - Theoretical Studies and Numerical Investigations. SAE Paper 2017-01-1555, 2017.

[11] Gidlewski, M., Jemioł, L. \& Żardecki, D., Simulation investigation of the dynamics of the process of sudden obstacle avoiding by a motor vehicle. The Archives of Automotive Engineering, 73(3), 2016.

[12] Gidlewski, M. \& Żardecki, D., Investigation of vehicle motion control process due to the linearization of the lateral dynamics reference model used in the controller. Mechanics Research Communications, 82, 2017.

[13] Gidlewski, M. \& Żardecki, D., Simulation investigations of lane change process with automatic steering system. Proceedings of 25th ESV'2017 Conference in Detroit, USA, available on the Internet.

[14] Andrzejewski, R. \& Awreicewicz, J., Nonlinear Dynamics of Wheeled Vehicle. Springer, NY 2003.

[15] Gidlewski, M., Model of a dual axis heavy truck for handling studies in complex road situations. 11th European Automotive Congress, Budapest 2007. 